of an increase in salary, but a revaluation of the teacher's functions.

\section{Inheritance of Human Characters}

IT is fascinating to examine our friends for hereditary characters which are, so far as we know, innocuous. Taste blindness, position of thumbs when the hands are clasped, and beating time with the left or the right foot are among the characters which have previously been reported as being inherited. K. A. Stiles and J. Schalck (J. Hered., 36, 211 ; 1945) add another character for such analysis. They show that the curvature of the forefinger towards the ulnar side is inherited, probably as a dominant. It may show unilateral expression, but sometimes involves both hands and more than one finger. It is not pathological. A further inherited character is olfactory blindness, tested through three generations by R. C. Mainland (J. Hered., 36, 144 ; 1945). The inheritance is probably by an autosomal dominant gene. The affected individual cannot smell oil of cloves, lysol, oil of cedarwood, amyl propionate and oil of annise; he could not distinguish between sour and sweet chocolate or between cloves and cinnamon. The phenyl-thio-carbamide test was normal.

\section{A Human Mosaic}

M. Zlotnikoff (J. Hered., 36, $136 ; 1945)$ has described a remarkable case of a woman who, in her own words, describes herself as a new species arising from a mutation in the two blastomere stage or as a blastomatous variation. The left side of the body is brown, café au lait, or crimson in colour; the right side is completely normal. The median line is strictly delimiting. The left side is bald, whereas the right side is normal. Eye colour is grey on the right and chestnut on the left. Hair colour is red and chestnut respectively. Perspiration and reactions to pilocarpine and atropine are normal on the left, but on the right side there was a noticeable lack of reaction. The blood pressure difference rose to $25 \mathrm{~mm}$.

\section{The Kamerlingh Onnes Laboratory}

SrNCE May 1940 the distribution of the communications of the Kamerlingh Onnes Laboratory of the University of Leyden has been restricted to the Netherlands; but a general distribution has now been resumed. So far Nos. 257 to 260 and Supplements 87 to 90 inclusive have appeared, containing reprints of papers published mainly in Physica during the years 1939-41. There are several papers by W. H. Keesom and co-workers dealing with the properties of liquid helium, and with specific heats at low temperatures. W. J. de Haas, H. B. G. Casimir and others have investigated the thermal conductivity of lead, specific heats at low temperatures, adiabatic demagnetization and the magnetic properties of several substances. There are also four papers by Jean Becquerel describing experiments on magnetic rotatory power.

\section{Conference on Pulverized Fuel}

ThE Institute of Fuel is arranging a Conference on Pulverized Fuel to take place in May 1947. The object is to collect up-to-date information on the preparation and use of pulverized fuel, including its advantages and disadvantages compared with other forms of fuel. It is hoped to cover the whole field, including steam raising, cement kilns, metallurgical and other furnaces, and details of developments in pulverized fuel practice throughout the world. The aim is to make available independent authoritative information on all aspects of pulverized fuel production and firing for the guidance of users and potential users of the system, and through the experience of present users to assist manufacturers in the development of design of pulverized fuel equipment. The Conference will also provide useful authoritative information for the use of the Ministry of Fuel and Power and the National Coal Board in their deliberations upon the most efficient preparation of coal for the market. It will also indicate problems to which research in this field might be directed with advantage, although the primary aim of the Conference is to deal with essentially practical problems in the use of pulverized fuel.

\section{University of Glasgow: Appointments}

DR. J. C. Speakman, formerly lecturer in chemistry at the University of Sheffield, who has been appointed lecturer in chemistry at the University of Glasgow, took up his new duties at the beginning of the present term. Messrs. F. D. Gunstone, of the University of Liverpool, and R. I. Reed, of University College, London, have been appointed to junior lectureships in chemistry as from the beginning of next session. Dr. G. M. Badger and Dr. J. D. P. Graham have taken up appointments as I.C.I. research fellows at Glasgow, in chemistry and pharmacology, respectively. Dr. Badger, who is an Australian, served in the Royal Navy during the War, and Dr. Graham served in the Royal Army Medical Corps.

\section{Announcements}

Messrs. E. R. WATts AND Son, Ltd., announce that they have acquired the business of Messrs. James Swift and Son, Ltd. The connexion between these two companies dates back over a hundred years, when Mr. Edwin Watts, founder of E. R. Watts and Son, Ltd., and Mr. James Swift, founder of James Swift and Son, Ltd., were both apprenticed at the mathematical instrument-making firm of Swaine's in the Waterloo Road, London. The bond of friendship so formed was maintained between the two families until the untimely deaths of Mr. Mansell James Swift, and his son, Mr. Mansell Powell John Swift, both in October 1942. Messrs. James Swift and Son, Ltd., will continue to trade under their own name, but it is hoped that the production facilities of Messrs. Watts will enable them to play their part in satisfying the need for microscopes in the next few years.

VoL. 2 of the Transactions of the All-Union Conference on Analytical Chemistry (Moscow : Acad. Sci. U.S.S.R. Section of Chemical Sciences, 1943) contains a number of papers of interest to analytical chemists. Each article deals with a special problem, and new methods and apparatus are discussed. The principal subjects of papers are: analysis of ferro-alloys, spectroscopic analysis, photoelectric analysis, determination of germanium in coal ash, and polarographic methods as applied to various substances.

Erratum. In the heading of the table accompanying the communication entitled "Effect of Heat on Wool, Cotton and Nylon", Nature of June I, p. 735, for " $150^{\circ} \mathrm{F}$." read " $150^{\circ} \mathrm{C}$.". 